\title{
A Case Study of Explosion A Single Solar Burst Type III and IV Due to Active Region AR1890
}

\author{
Z. S. Hamidi ${ }^{1, *}$, M. B. Ibrahim ${ }^{1}$, N. N. M. Shariff ${ }^{2}$, C. Monstein ${ }^{3}$ \\ ${ }^{1}$ School of Physics and Material Sciences, Faculty of Sciences, MARA University of Technology, \\ 40450, Shah Alam, Selangor, Malaysia \\ ${ }^{2}$ Academy of Contemporary Islamic Studies (ACIS), MARA University of Technology, \\ 40450, Shah Alam, Selangor, Malaysia \\ ${ }^{3}$ Institute of Astronomy, Wolfgang-Pauli-Strasse 27, Building HIT, \\ Floor J, CH-8093 Zurich, Switzerland \\ *E-mail address: zetysh@salam.uitm.edu.my
}

\begin{abstract}
Using data from a BLEIN Callisto site, we aim to provide a comprehensive description of the synopsis formation and dynamics of a a single solar burst type III and IV event due to active region AR1890. This eruption has started since 14:15 UT with a formation of type III solar burst. To investigate the importance of the role of type III solar burst can potentially form a type IV solar burst, the literature review of both bursts is outlined in detailed. The orientation and position of AR1890 make the explosion of a class C-solar flare is not directly to the Earth. Nevertheless, it is clear that the interactions of others sunspots such as AR1893,AR1895,AR1896, AR1897 and AR1898 should be studied in detail to understand what makes the type III burst formed before the type IV solar burst.
\end{abstract}

Keywords: Sun; solar burst; III; IV; radio region; X-ray region; solar flare; active region

\section{INTRODUCTION}

Under certain circumstances, type IV burst can be as a beginning of solar flare explosion [1-3]. During emission stripes the source drift over distances up to several $\times 10^{4}$ $\mathrm{km}$, with apparent velocities up to $10^{5} \mathrm{~km} \mathrm{~s}^{-1}$ [4]. The direction of the source motion at a given frequency is on average found to be perpendicular between broadband radio pulsations (BBP) and zebra patterns $(\mathrm{ZP})$ sources. [5]. BBP does show high frequency $\operatorname{drift}\left(\approx-250 \mathrm{MHz} \mathrm{s}^{-1}\right)$. [6]. These solar type IV radio emissions is dominant a few days before solar flare and Coronal Mass Ejections explosion [7-9].

Type III bursts trace electron streams as they propagate along open field lines from flaring regions near the Sun into the interplanetary medium.In general, solar radio burst type III solar burst is the most the most common type [10] with range of frequency from 500-10 $\mathrm{MHz}$ [11-13].

This emission is probably from a part of the electron population that remains trapped in closed magnetic loops [14]. Usually, a fast drift (type III) solar radio bursts are synchronized in time with solar flares [15]. A previous study has shown that the type III are generated in a weak-field region comes from the absence or low degree of circular polarization of the bursts 
[16]. Langmuir waves active region radio emissions is believed to be a main subject that relevant with a type III burst [17-21].

These forces drive the plasma to a state unstable to the growth the beam-plasma interactions, is believed to generating these waves [22,23]. This type is very synonymous at the meter and decimeter wavelengths [24,25]. Early stage of solar flares may indicate that open field lines are an essential part of models for energy release by magnetic fields [26,27]. Detailed analysis of the Sun in radio and x-ray region to understand the distribution of high and low energy [28-31]. We will highlight the solar flare and solar bursts in both electromagnetic radiation.

\section{SOLAR FLARE OBSERVATION}

During a major space weather event which includes a burst of solar [32-34]. Compact Astronomical Low cost, Low frequency Instrument for Spectroscopy and Transportable Observatory (CALLISTO) from BLEIN with the 7 meter dish telescope at ETH, Zurich is being used to monitor the solar burst. [35,36].

We also have constructed a log-periodic antenna is a broadband, multi-element, unidirectional, narrow-beam antenna that has impedance and radiation characteristics that are regularly repetitive as a logarithmic function of the excitation frequency [34,37-40]. The Log Periodic Dipole Antenna has been constructed from 45 - $870 \mathrm{MHz}$ [41,44].

The CALLISTO spectrometer is a low-cost radio spectrometer used to monitor metric and decametric radio bursts [45-49]. We select the range of $150 \mathrm{MHz}$ till $900 \mathrm{MHz}$ for this data [50-52].

This range has a very minimum interference at Blein, Switzerland site [53,54]. Selected the data from the $150 \mathrm{MHz}$ till $900 \mathrm{MHz}$ region seems this is the best range with a very minimum of Radio Frequency Interference (RFI) [54-63]. The next section will highlight the detailed analysis of solar flares in an X-ray and radio region to evaluate the distribution of high and low energy [41].

\section{RESULTS AND ANALYSIS}

Based on the observation, we found that an individual type III solar burst with a fast drift pattern was formed at 14:17 UT with high intensity. This burst is an indicator of formation of solar flare. The burst is drifting from $200-600 \mathrm{MHz}$. Before the formation, it is clear that a complex of type III is also appearing. However, it did not take a long time of duration. The type IV solar burst with duration of 7 minutes can can be observed from $280-$ $900 \mathrm{MHz}$. The class of $\mathrm{C}$ solar flare is evolving at this point. This type is the slow drift burst and could take a few hours. The Sun remains active during this time and solar flare C.9 class formed at 4:00 UT. This flare is the highest point during that day. After introducing our data, we will provide a description of certain parameter of solar burst based on calculation, energy for the burst, the energy of the burst is in the range of $1.524 \times 10^{-25} \mathrm{~J}$ to $2.195 \times 10^{-25} \mathrm{~J}$. 


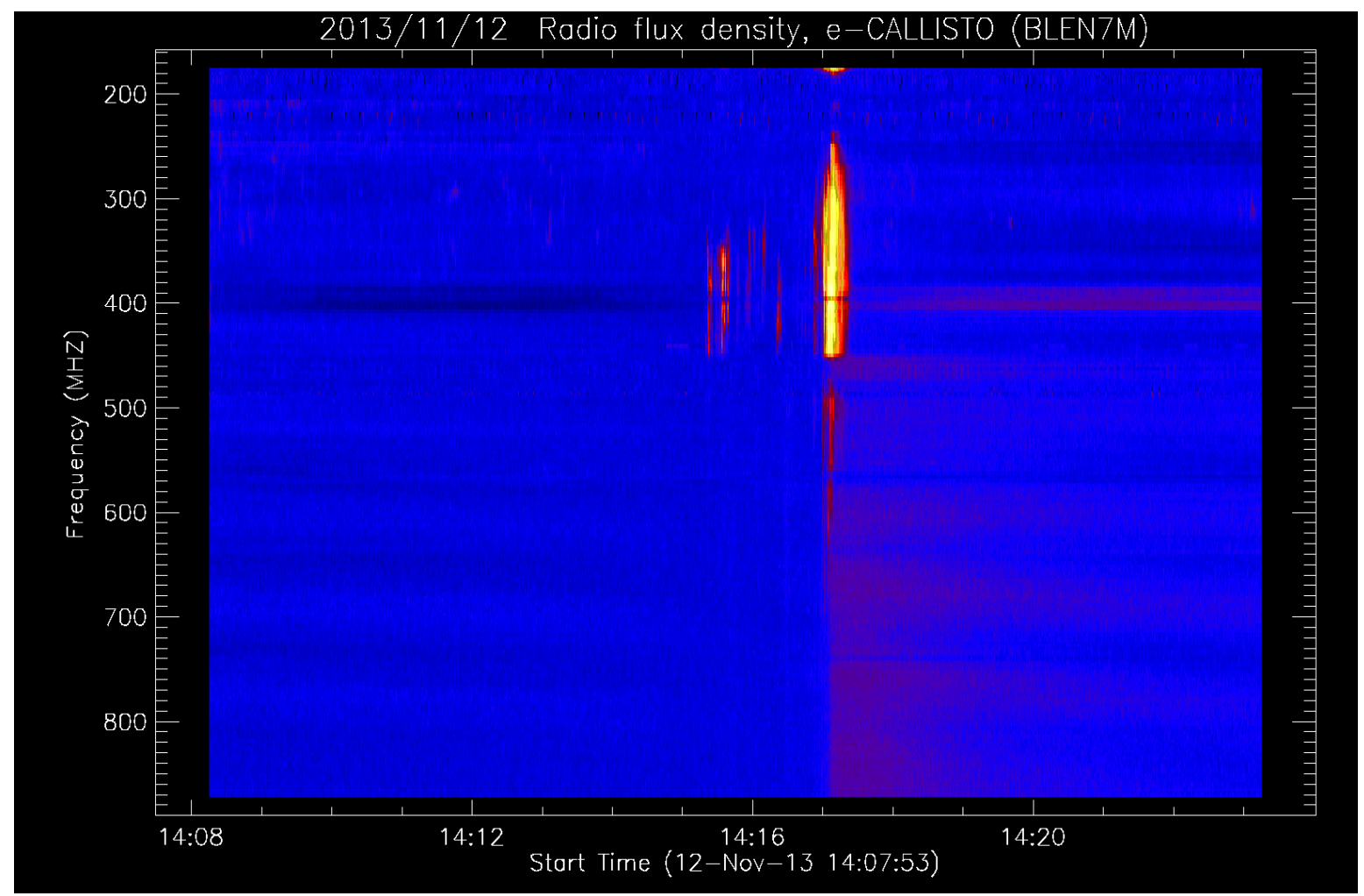

Figure 1. The continuous solar radio burst type III at 14:17 (Credited to: E-Callisto network (BLEIN7M)).

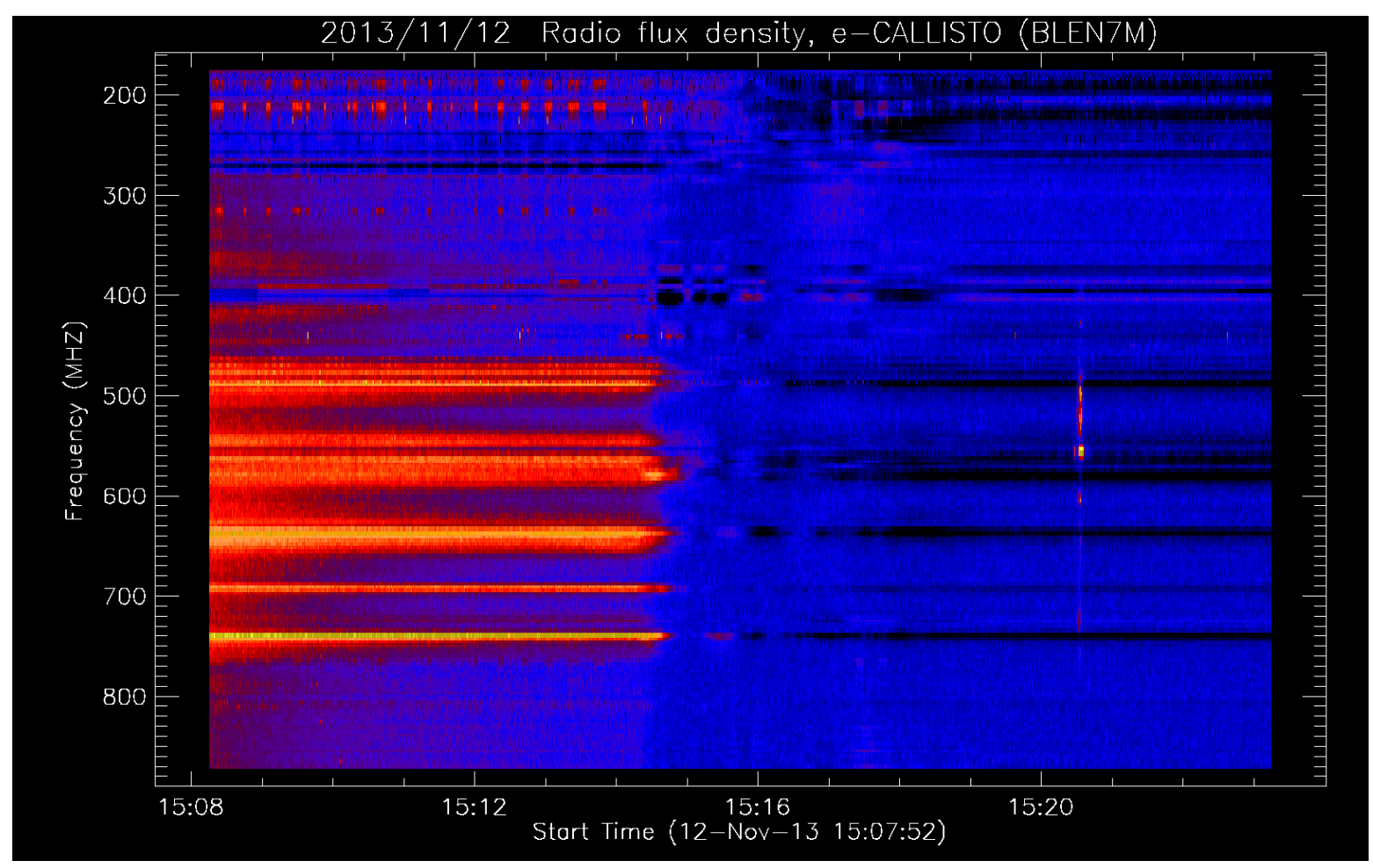

Figure 2. A type IV solar radio burst appears 7 minutes after solar radio burst type IV (Credited to: E-Callisto network (BLEIN7M)). 
The energy released is higher than first case and the second case because the burst happen in the higher frequency. Based on the theoretical point of view, the drift velocity also calculated as shown below:

$$
\begin{gathered}
\mathrm{E}=h f \\
=\left(6.626 \times 10^{-34} \mathrm{~m}^{2} \mathrm{~kg} / \mathrm{s}\right)\left(230 \times 10^{6} \mathrm{~Hz}\right) \\
=1.524 \times 10^{-25} \mathrm{~J} \\
=2.44 \times 10^{-44} \mathrm{Ev} \\
\mathrm{E}=h f \\
=\left(6.626 \times 10^{-34} \mathrm{~m}^{2} \mathrm{~kg} / \mathrm{s}\right)\left(440 \times 10^{6} \mathrm{~Hz}\right) \\
=2.915 \times 10^{-25} \mathrm{~J} \\
=4.66 \times 10^{-44} \mathrm{eV} \\
\frac{d f}{d t}=\frac{f \text { high }-f \text { low }}{t \text { high }-t \text { low }} \\
=52.5 \mathrm{MHz} / \mathrm{second}
\end{gathered}
$$

The plasma frequency calculated,

$$
\begin{gathered}
\mathrm{Vp}=\underline{\sqrt{e 2 N e}} \\
4 \pi \varepsilon_{0} \mathrm{~m}_{\mathrm{e}} \\
=1.06 \times 10^{4} \mathrm{~Hz}
\end{gathered}
$$

In addition, data from the Space Weather Web Site is used. Owing to the complex structure of Active Region 1890, the spatial distribution of the dynamical energy transport in the region is very complex. There are other five active regions, mostly at the West part of the Sun. Based on the analysis, the speed of the solar wind also exceeds $386.9 \mathrm{~km} / \mathrm{sec}$ with 1.4 $\mathrm{g} / \mathrm{cm}^{3}$ density of proton in the solar corona. The radio flux also shows 104 SFU. During that day, there are six active regions or sunspot spotted. Moreover, there are a large coronal holes on the Earth- facing side of the sun. The Solar flare class C4 is continuously being observed in X-ray region for 24 hours since 1943 UT and a maximum class C4 is detected on 1943 UT. The active region 1890 is responsible to eject solar flares. As we know, the probability of solar Emissions is high when a large sunspot group is present, as for this event, the number of sunspots spotted during the day is 104 with 164 SFU. Based on the figure, it is shown that the formation of burst at 13.48 UT. From the figure, it is found the sunspot 1890 responsible to eject the Solar flare. Although, it is said that sunspot 1890 is decaying, but it still has a magnetic field that ejects X-class solar flares. 




Figure 3. Active region (1890) in visible wavelength and the image of the Sun by X-ray from Space Weather Website (Credited to: NOAA/ SWPC).

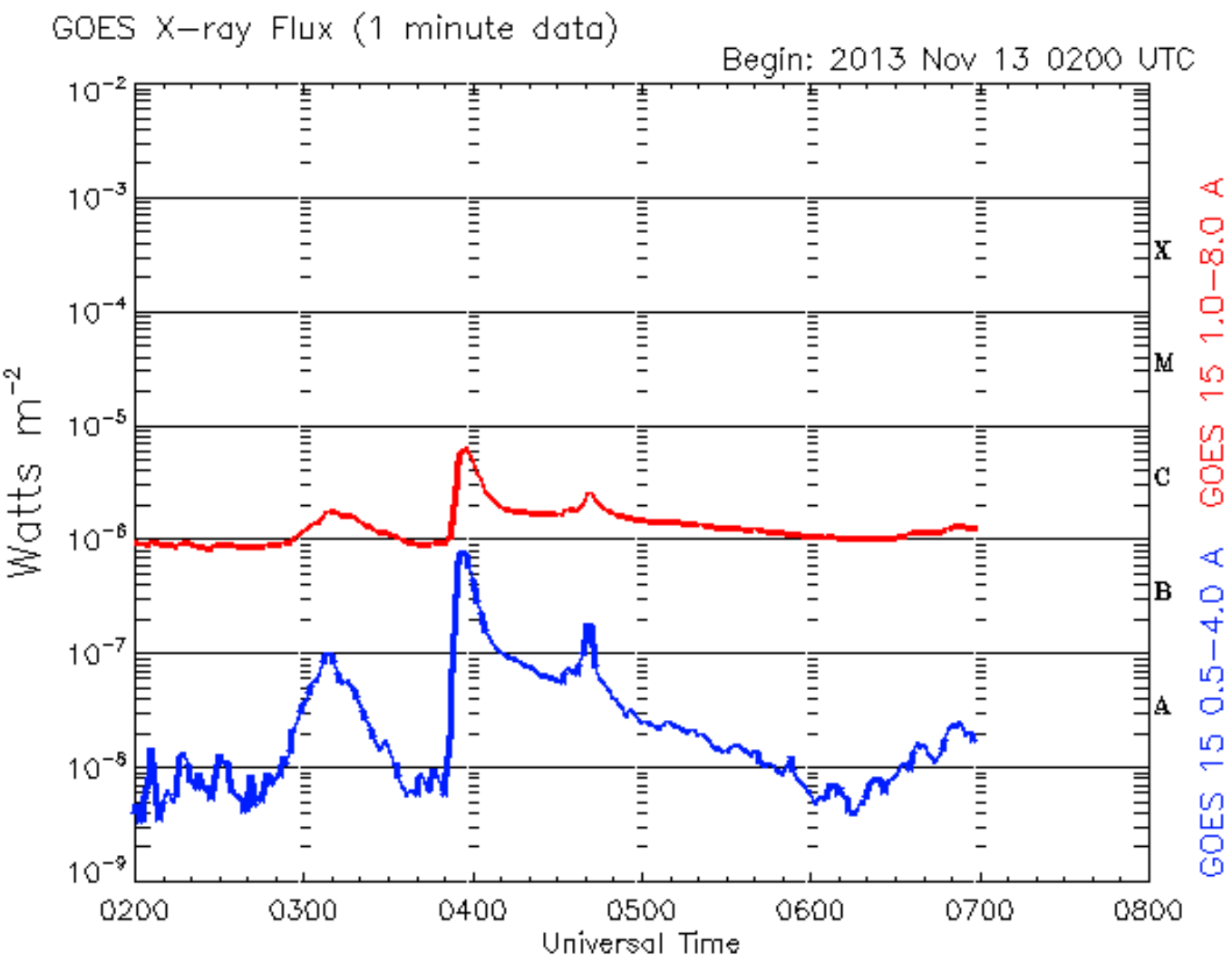

Updated 2013 Nov 130700 UTC

NOAA/SWPC Boulder, CO USA

Figure 4. The variability of solar flare during $13^{\text {th }}$ November 2013 (Credited to NOAA Space Environment Centre). 
From the calculation the drift rate and plasma frequency is $52.5 \mathrm{MHz} / \mathrm{second}$ and $1.06 \times$ $10^{4}$ respectively. In this event, the burst occurred as low frequency compared to the previous events, but this event occurred longer compared to the previous event. It has been observed that the solar wind and density is low as the plasma frequency also low. It is found when the number of electron and proton ejected in the solar wind is low, so the plasma frequency low, hence the drift velocity and total energy also low. This is because the particular particles as electron or proton each bring respective energies. As the energy is carried low, the energy produced also low.

\section{CONCLUDING REMARKS}

The orientation and position of AR1890 make the explosion of a class C-solar flare is not directly to the Earth. Nevertheless, it is clear that the interactions of others sunpots such as AR1893, AR1895, AR1896, AR1897 and AR1898 should be studied in detail to understand what makes the type III burst formed before the type IV solar burst.

\section{Acknowledgement}

We are grateful to CALLISTO network, STEREO, LASCO,SDO/AIA, NOAA and SWPC make their data available online. This work was partially supported by the FRGS (600 RMI/FRGS 5/3 2012) UiTM grants. Special thanks to the National Space Agency and the National Space Centre for giving us a site to set up this project and support this project. Solar burst monitoring is a project of cooperation between the Institute of Astronomy, ETH Zurich, and FHNW Windisch, Switzerland, MARA University of Technology and University of Malaya. This paper also used NOAA Space Weather Prediction Centre (SWPC) for the sunspot, radio flux and solar flare data for comparison purpose. The research has made use of the National Space Centre Facility and a part of an initiative of the International Space Weather Initiative (ISWI) program.

\section{Biography}

Dr Zety Sharizat Hamidi is currently a senior lecturer and focused in Solar Astrophysics research specifically in radio astrophysics at the School of Physics and Material Sciences, Faculty of Sciences, MARA University of Technology, 40450, Shah Alam, Selangor, Malaysia. Involve a project under the International Space Weather Initiative (ISWI) since 2010.

M. B. Ibrahim is an undergraduate Physics student at the School of Physics and Material Sciences, Faculty of Sciences, MARA University of Technology, 40450, Shah Alam, Selangor, Malaysia.

Dr Nur Nafhatun Md Shariff is a senior lecturer in Academy of Contemporary Islamic Studies (ACIS), MARA University of Technology, 40450, Shah Alam, Selangor, Malaysia.Her current research is more on sustainability; environmental aspect. She is looking forward for cross-field research, i.e. solar astrophysics, light pollution measurement (mapping) and religious studies.

C. Monstein is a senior Engineer at Institute of Astronomy, Wolfgang-Pauli-Strasse 27, Building HIT, Floor J, $\mathrm{CH}-8093$ Zurich, Switzerland and one of the researchers who initiated the CALLISTO system around the world. 


\section{References}

[1] Z. Hamidi, Z. Abidin, Z. Ibrahim, C. Monstein, N. Shariff, M. Sabaghi, International Journal of Fundamental Physical Sciences 2 (2012).

[2] Z. Hamidi, N. Shariff, C. Monstein, Disturbances of Solar Eruption From Active Region AR1613, (2014).

[3] Z. Hamidi, N. Shariff, International Letters of Chemistry, Physics and Astronomy 7 (2014) 30-36.

[4] Z. Hamidi, Z. Abidin, Z. Ibrahim, C. Monstein, N. Shariff, Signal Detection Performed by Log Periodic Dipole Antenna (LPDA) in Solar Monitoring, International Journal of Fundamental Physical Sciences (2012).

[5] H. Aurass, Coronal Physics from Radio and Space Observations, in: I.G. Trottet (Ed.), Lecture Notes in Physics, Springer, Berlin, 1997.

[6] A.D. Fokker, Space Science Reviews 2 (1963) 70-90.

[7] C.W. Young, C.L. Spencer, G.E. Moreton, J.A. Roberts, Astrophys. J. 133 (1961).

[8] Ellis, Australian J .Phys. 22 (1969) 167.

[9] D.J. McLean, A.N.R. Labrum, Solar Radiophysics, Cambridge University Press, Cambridge, 1985.

[10] J.P. Wild, Smerd S.F., Weiss, A.A., Solar Burst, Ann. Rev. Astron. Astrophysics 1 (1963) 291-366.

[11] Z. Hamidi, N. Shariff, The Propagation of An Impulsive Coronal Mass Ejections (CMEs) due to the High Solar Flares and Moreton Waves, (2014).

[12] Z. Hamidi, U. Ibrahim, U.F. Salwa, Z. Abidin, Z. Ibrahim, N. Shariff, International Journal of Fundamental Physical Sciences 3 (2013).

[13] Z. Hamidi, N. Shariff, C. Monstein, First Light Detection of A Single Solar Radio Burst Type III Due To Solar Flare Event, (2014).

[14] G.A. Dulk, Type III solar radio bursts at long wavelengths, in: R. Stone, E. Weiler, M. Goldstein (Eds.), Geophys. Monogr., 2000.

[15] G. Swarup, P.H. Stone, A. Maxwell, ApJ 131 (1960).

[16] Z. Hamidi, N. Shariff, C. Monstein, Scenario of Solar Radio Burst Type III During Solar Eclipse on 14 th November 2012.

[17] G.B.a.L. Gelfreikh, B. I., Soviet Astron. 23 (1979).

[18] P. Lantos, Sol. Phys. 22 (1972).

[19] A. Vourlidas, Bastian, T. S., Nitta, N., Aschwanden M. J., Sol. Phys. 163 (1996).

[20] E.Y. Zlotnik, Soviet Astron. 12 (1968).

[21] V.V. Zheleznyakov, Radio Emission of the Sun and Planets (1970).

[22] Z. Hamidi, N. Shariff, C. Monstein, W.W. Zulkifli, M. Ibrahim, N. Arifin, N. Amran, International Letters of Chemistry, Physics and Astronomy 8 (2014) 13-19. 
[23] Z. Hamidi, N. Shariff, C. Monstein, Statistical Study of Nine Months Distribution of Solar Flares, (2014).

[24] Z. Hamidi, Z. Abidin, Z. Ibrahim, C. Monstein, N. Shariff, International Journal of Fundamental Physical Sciencea 2 (2012) 3.

[25] Z. Hamidi, N. Shariff, International Letters of Chemistry, Physics and Astronomy 4 (2014) 29-36.

[26] S.M. White, Asian Journal of Physics 16 (2007) 189-207.

[27] Z.S. Hamidi, N.N.M. Shariff, International Letters of Chemistry, Physics and Astronomy 5 (2014) 32-42.

[28] Z.S. Hamidi, N.N.M. Shariff, M.F. Ali, C. Monstein, W.N.A.W. Zulkifli, M.B. Ibrahim, N.S. Arifin, N.A. Amran, International Letters of Chemistry, Physics and Astronomy 9 (2014) 84-92.

[29] Z.S. Hamidi, N.N.M. Shariff, F.N.Z. Ulum, Z.Z. Abidin, Z.A. Ibrahim, International Journal of Astronomy 5 (2012) 101-106.

[30] Z. Hamidi, International Letters of Chemistry, Physics and Astronomy 16 (2014) 1-85.

[31] Z. Hamidi, C. Monstein, N. Shariff, Radio Observation of Coronal Mass Ejections (CMEs) Due to Flare Related Phenomenon on 7 th March 2012, (2012).

[32] Z. Hamidi, N. Shariff, Enormous Eruption of 2.2 X-class Solar Flares on 10 th June 2014.

[33] Z. Hamidi, N. Shariff, C. Monstein, Understanding Climate Changes in Malaysia Through Space Weather Study, International Letters of Natural Sciences (2014).

[34] Z. Hamidi, N. Shariff, The Mechanism of Signal Processing of Solar Radio Burst Data in E-CALLISTO Network (Malaysia), International Letters of Chemistry, Physics and Astronomy (2014).

[35] Z. Hamidi, et al., Malaysian Journal of Science and Technology Studies 9 (2013) 15-22.

[36] Z.S. Hamidi, N. Shariff, Z. Abidin, Z. Ibrahim, C. Monstein, Middle-East Journal of Scientific Research 12 (2012) 6.

[37] Z.S.Hamidi, N.N.M.Shariff, Evaluation of Signal to Noise Ratio (SNR) of Log Periodic Dipole Antenna (LPDA) Business Engineering and Industrial Applications Colloquium 2013, IEEE, Langkawi, Malaysia, 2013, pp. 434-438.

[38] Z. Hamidi, N. Shariff, International Letters of Chemistry, Physics and Astronomy 7 (2014) 21-29.

[39] Z. Hamidi, N. Shariff, C. Monstein, The Different Between the Temperature of the Solar Burst at the Feed Point of the Log Periodic Dipole Antenna (LPDA) and the CALLISTO Spectrometer, (2014).

[40] N. Hashim, Z. Abidin, U. Ibrahim, R. Umar, M. Hassan, Z. Rosli, Z. Hamidi, Z. Ibrahim, Radio Astronomy in Malaysia: Current Status and Outreach Activities, Astronomical Society of the Pacific Conference Series, 2011, pp. 355.

[41] Z.S. Hamidi, Z. Ibrahim, Z. Abidin, M. Maulud, N. Radzin, N. Hamzan, N. Anim, N. Shariff, International Journal of Applied Physics and Mathematics 2 (2011) 3. 
[42] Z. Hamidi, N. Shariff, C. Monstein, Evaluation of Spectral Overview and Radio Frequency Interference (RFI) Sources at Four Different Sites in CALLISTO Network at the Narrow Band Solar Monitoring Region, (2014).

[43] Z.S. Hamidi, N.N.M. Shariff, C. Monstein, Z.A. Ibrahim, International Letters of Chemistry, Physics and Astronomy 7 (2014) 37-44.

[44] Z.S. Hamidi, N.N.M. Shariff, Z.A. Ibrahim, Z.Z. Abidin, SOLAR STUDIES IN RADIO EMISSION AND OPTICAL PHOTOMETRY, University of Malaya Publisher, 2013.

[45] Z.S.Hamidi, S. Chumiran, A. Mohamad, N. Shariff, Z. Ibrahim, N. Radzin, N. Hamzan, N. Anim, A. Alias, American Journal of Modern Physics 2 (2013) 4.

[46] Z.S.Hamidi, Z. Abidin, Z. Ibrahim, N. Shariff, C. Monstein, International Journal of Engineering Research and Development 3 (2012) 36-39.

[47] Z.S.Hamidi, Z. Abidin, Z. Ibrahim, C. Monstein, N. Shariff, International Journal of Fundamental Physical Sciences 2 (2012) 32-34.

[48] Z.S.Hamidi, N.M.Anim, N. N.S.Hakimi, N.Hamzan, A.Mokhtar, N.Syukri, S.Rohizat, I.Sukma, Z.A. Ibrahim, Z.Z.Abidin, N.N.M.Shariff, C.Monstein, International Journal of Fundamental Physical Sciences 2 (2012) 4.

[49] Z.S. Hamidi, N.N.M. Shariff, International Journal of Science and Mathematics 2 (2014) 3.

[50] Z.S. Hamidi, Z. Abidin, Z. Ibrahim, N. Shariff, Indication of radio frequency interference (RFI) sources for solar burst monitoring in Malaysia, ICPAP 2011, AIP Publisher, Indonesia, 2012, pp. 6.

[51] Z.S. Hamidi, N.N.M. Shariff, C. Monstein, The International Journal of Engineering 1 (2012) 3 .

[52] Z. Hamidi, N. Shariff, C. Monstein, W.W. Zulkifli, M. Ibrahim, N. Arifin, N. Amran, Observation of the Radio Frequency Interference (RFI) at the National Space Centre, Malaysia, International Letters of Natural Sciences (2014).

[53] Z.S. Hamidi, Z.Z. Abidin, Z.A. Ibrahim, N.N.M. Shariff, U.F.S.U. Ibrahim, R. Umar, Preliminary analysis of investigation Radio Frequency Interference (RFI) profile analysis at Universiti Teknologi MARA, IEEE, 2011, pp. 311-313.

[54] R. Umar, Z. Abidin, Z. Ibrahim, N. Gasiprong, K. Asanok, S. Nammahachak, S. Aukkaravittayapun, P. Somboopon, A. Prasit, N. Prasert, Middle East Journal of Scientific Research 14 (2013).

[55] Z.S.Hamidi, N.N.M.Shariff, R.Umar, Malaysia Thailand Journal of Physics 3 (2012) 6.

[56] R. Umar, Z.Z. Abidin, Z.A. Ibrahim, M.S.R. Hassan, Z. Rosli, Z.S. Hamidi, AIP Conference Proceedings 1454 (2012) 39.

[57] N. Anim, Z. Hamidi, Z. Abidin, C. Monstein, N. Rohizat, Radio frequency interference affecting type III solar burst observations, 2012 NATIONAL PHYSICS

CONFERENCE: (PERFIK 2012), American Institute of Physics, 2013, pp. 82-86.

[58] Z. Hamidi, N. Shariff, C. Monstein, International Letters of Chemistry, Physics and Astronomy 10 (2014) 38-45. 
[59] Z. S. Hamidi, N. N. M. Shariff, C. Monstein, International Letters of Chemistry, Physics and Astronomy 14(1) (2014) 1-11

[60] Z. S. Hamidi, N. N. M. Shariff, International Letters of Chemistry, Physics and Astronomy 14(1) (2014) 118-126

[61] Z. S. Hamidi, N. N. M. Shariff, C. Monstein, International Letters of Chemistry, Physics and Astronomy 14(2) (2014) 208-217

[62] Z. S. Hamidi, N. N. M. Shariff, International Letters of Chemistry, Physics and Astronomy 15 (2014) 30-38.

[63] Z. S. Hamidi, N. N. M. Shariff, C. Monstein, International Letters of Chemistry, Physics and Astronomy 18 (2014) 103-112. 